\title{
Chemical profiles of PM emitted from the iron and steel industry in Northern China
}

Yangyang Guo ${ }^{1}$, Xiang Gao ${ }^{1}$, Tingyu Zhu ${ }^{1,2^{*}}$, Lei Luo ${ }^{1,3}$, Yang Zheng ${ }^{1}$

${ }^{1}$ Beijing Engineering Research Centre of Process Pollution Control, National Engineering

Laboratory for Hydrometallurgical Cleaner Production Technology, Institute of Process

Engineering, Chinese Academy of Sciences, Beijing 100190, China

${ }^{2}$ Center for Excellence in Regional Atmospheric Environment, Institute of Urban Environment, Chinese Academy of Sciences, Xiamen 361021, China

${ }^{3}$ School of Chemistry and Chemical Engineering, Guizhou University, Guiyang, Guizhou 550025, China
Abstract
Source-level sampling methods were adopted in this study to sample six iron and steel plants referring four main manufacturing processes, with over 150 samples collected and measured in this study, the latest data for iron and steel industry in China has been demonstrated. The emission factors of $\mathrm{CO}_{2}, \mathrm{CO}, \mathrm{SO}_{2}, \mathrm{NO}_{x}, \mathrm{TSP}$, $\mathrm{PM}_{2.5}$ and $\mathrm{PM}_{10}$ were calculated, and the majority of pollutants were emitted from the sintering process. The virtual impactor divided the PM sample into three size fractions for chemical profiles and the profiles indicate that $\mathrm{SO}_{4}{ }^{2-}, \mathrm{NH}_{4}{ }^{+}$and $\mathrm{OC}$ distribute more into fine particles. The elements in PM from the sintering, pelletizing, puddling

\footnotetext{
Tel./fax:+86-10-82544821

E-mail address: tyzhu@ipe.ac.cn (T. Zhu).
} 
and steelmaking processes were measured and compared using the coefficient of divergence. The divergence between $\mathrm{PM}_{2.5}$ and $\mathrm{PM}_{10}$ for the same process is not obvious, with $\mathrm{CD}$ values ranging from 0.1697 to 0.2578 . $\mathrm{PM}_{2.5}$ profiles of four process were notably different from one another, with $\mathrm{CD}$ values ranging from 0.4802 to 0.7500 . More efforts are needed to update the PM profiles in China. PAHs in PM were investigated, and most of the PAHs in PM are from the sintering process. The total PAH concentration in $\mathrm{PM}_{2.5}$ from the sintering process is $73.28 \pm 1.45 \mu \mathrm{g} / \mathrm{m}^{3}$ with a BaPE value calculated at $9.92 \mu \mathrm{g} / \mathrm{m}^{3}$.

Keywords: Iron and steel industry, PM source profiles, Emission factors, PAHs

\section{Introduction}

Chemical source profiles of particle matter (PM) are the foundation of atmospheric PM source apportionment, and the accuracy of the source apportionment is mainly tied to the source data input (Raman et al. 2007, Liu et al. 2014, Zhang et al. 2014). Unlike the SPECIATE database established by the US Environmental Protection Agency (Simon et al. 2010), the local PM source profile database of China is still unformed, limiting the effective control of pollutant emissions.

The PM profiles of regional fugitive dust (Ho et al. 2003, Xu et al. 2012, Kong et al. 2014, Chen et al. 2016, Elena et al. 2016), vehicles (Li et al. 2013, Stroe et al. 2014, Wu et al. 2015, Sahanavin 2016) and coal and bio-fuel combustion (Ciuta 2012, Ma et al. 2015, Li et al. 2016) have already been extensively investigated in China, while local industrial source information has seldom been reported. According to the statistical data reported by the Ministry of Environmental Protection of China, over $85 \%$ 
of $\mathrm{SO}_{2}, 65 \%$ of $\mathrm{NO}_{x}$ and $80 \%$ of $\mathrm{PM}$ were emitted from the industrial sources in 2014, the total industrial PM emission reached 14.561 million ton, making industrial source pollution control extremely critical to improve China's air quality.

Thermal power plant is the biggest industrial PM emission source in China with 2.355 million ton PM emitted in 2014, some studies related to the emission inventory (Ma et al. 2016), emission profile (Ai et al. 2011, Kong et al. 2013) and control technology (Zhao et al. 2014) have already been performed. The dilution sampling method has been adopted, with the basic consistent conclusion of that $\mathrm{PM}_{2.5}$ emissions from coal-fired plants include $\mathrm{Al}, \mathrm{Ca}, \mathrm{Fe}, \mathrm{K}, \mathrm{SO}_{4}{ }^{2-}, \mathrm{NH}_{4}{ }^{+}$and organic carbon (OC), while the absolute concentrations of these elements are influenced by the coal species and combustion conditions (Nielsen et al. 2002, Yi et al. 2006).

Apart from the thermal power plant, iron and steel manufacturing plants are the second biggest industrial PM emission source in China, the traditional long process of iron and steel plants has caused huge quantities of energy consumption and significant pollutants emission, with 1.02 million ton PM emitted in 2014. As for the PM profiles of iron and steel plants, so far there were no more than ten iron and steel plants been reported by the literature (Yang et al. 2002, Kong et al. 2011, Yang 2015, Wang et al. 2016), one reason may limited by the sampling method, another may caused by the complex processes of iron and steel manufacturing, the accurate source profiles is more difficult for iron and steel industry. The profiles for iron and steel plants are quite different because of the different industrial processes and manufacturing regions; $\mathrm{SO}_{4}{ }^{2-}, \mathrm{Cl}^{-}, \mathrm{K}, \mathrm{OC}$ and $\mathrm{Ca}$ are the main contributors at the sintering plant, while $\mathrm{Fe}$ and 
$\mathrm{Zn}$ dominate $\mathrm{PM}_{2.5}$ emissions from the smelting furnace plant (Amodio et al. 2013, Zheng et al. 2013). These significant discrepancies in chemical species are closely linked to many factors, meaning that the chemical profiles of the iron and steel industry are far from completion.

So far the published profiles of iron and steel plants in China are from 2009 to 2015, almost all the samples were collected after de-dusting facilities, only one profile in Shanghai (Zheng et al. 2013) takes the desulfurization into consideration. Sintering is the main pollutants emission source in iron and steel plants, the national emission standard for sintering flue gas (GB 28662-2012) has been published in 2012 and regulated the $\mathrm{SO}_{2}$ at $200 \mathrm{mg} / \mathrm{m}^{3}$ since 2015, also the total PM in iron and steel plant has been requested to be under $50 \mathrm{mg} / \mathrm{m}^{3}$, so with the establishment of the matching desulfurization and de-dusting facilities, PM profiles emitted from sintering machine to the air need to be updated to reflect the real emission status, this is one important point should be mentioned.

Considering the urgency of establishing the latest PM chemical profiles for the iron and steel industry, six iron and steel plants were all chosen with desulfurization and de-dusting facilities, the desulfurization methods include both the wet flue gas desulfurization and the semi-dry flue gas desulfurization, de-dusting methods include the electrostatic precipitator and the bag filter, most of these pollutants control facilities are installed after 2012. The locations of these plants were in Jing-Jin-Ji area of northern China, which possesses a quarter of the national iron and steel production, the steel annual production capacity ranges from 100 to 800 million ton, covering the 
typical local iron and steel industry. The sampling period is lasted from March to November 2015 , all the sampling work has been proceeded under fine days $\left(10 \sim 28^{\circ} \mathrm{C}\right)$, without rainy or snowy weather to avoid the sample pollution, the sampling sites are closely related to the latest pollutants control facilities, so the data in manuscript can reflect the real emission profiles at present, which is much more precious for developing the iron and steel industry profiles in China. Source-level sampling method were adopted to reflect real emission conditions, and the primary emission processes were comprehensively compared. The aim of this research is to focus on establishing and updating the chemical profiles of the iron and steel industry in northern China. Polycyclic aromatic hydrocarbons (PAHs) were also characterized in this work, providing the latest information for the PM source.

\section{Methodology}

\subsection{Sampling}

\subsubsection{Sampling sites description}

Six typical iron and steel plants in northern China were chosen based on production scale, location, production process, pollution control facilities and raw materials. The iron production capacity of these six plants are all above 100 million tons per year where those plants are located in northern China and use the traditional long production process. The details of the plants are shown in Table 1.

\subsubsection{Flue gas parameters}

The concentrations of flue gas components were detected using a flue gas analyser (Testo350, Germany). The resolution of $\mathrm{O}_{2}$ and $\mathrm{CO}_{2}$ measurements are 0.01 
Vol.\%; $\mathrm{CO}$ is $1 \mathrm{ppm}$; and $\mathrm{NO}_{x}$ and $\mathrm{SO}_{2}$ are $0.1 \mathrm{ppm}$. Flue gas temperature, flow rate and total suspended particulate (TSP) concentrations were determined using an automatic dust sampling instrument (3012H, Qingdao Laoying Co. China).

\subsubsection{Particulate matter sampling description}

The TSP was sampled by the automatic dust sampling instrument, the sampling flow rate was 10-60 L/min, and TSP concentrations were collected using a quartz filter cartridge ( $\varphi 28 \times 70 \mathrm{~mm}$, Qingdao Laoying Co. China) and weighed on a sensitive microbalance (MS105DU, METTLER) with a sensitivity of $\pm 0.01 \mathrm{mg}$.

A two stage virtual impactor was adopted to collect $\mathrm{PM}_{10} / \mathrm{PM}_{2.5}$ from flue gas, which was self-developed by Tsinghua University (Jiang et al. 2014). The PM has been sieved into three levels through the virtual impactor, including $\mathrm{PM}_{2.5}$ (aerodynamic diameter less than $2.5 \mu \mathrm{m}$ ), $\mathrm{PM}_{10}$ (aerodynamic diameter less than 10 $\mu \mathrm{m})$ and $\mathrm{PM}_{>10}$ (aerodynamic diameter larger than $10 \mu \mathrm{m}$ ). The virtual impactor showed highly satisfactory performance for $\mathrm{PM}_{2.5}$ mass concentrations and separation efficiency within the investigated range of mass concentrations and ambient conditions (Wada et al. 2016). The collection efficiency curve meets the requirement of ISO 13271, 2012 for virtual impactors. The diameter of this cylindrical virtual impactor is $74 \mathrm{~mm}$, smaller than the diameter of the sampling port in most industrial sources in China. Taking the sampling sites of the sintering process as an example: the gas flow is stable, and the sampling site was chosen at the end of the pollution control facility, reflecting the PM actually emitted to the ambient environment (Figure 1).

\subsubsection{Filters pre-treatment and storage}



parallel samples were collected using quartz-fibre filters ( $\varphi 37 \mathrm{~mm}$, Pall Corp. USA); the second parallel sample was collected by using Teflon-membrane filters $(\varphi 37 \mathrm{~mm}$, Pall Corp. USA). Blanks filters were treated in the same manner as the PM samples. compounds prior to sampling. Calcined quartz fibre filters and Teflon-membrane filters were equilibrated in a constant temperature $\left(25^{\circ} \mathrm{C}\right)$ and humidity $(\mathrm{RH}=50 \%)$ system for $48 \mathrm{~h}$ before gravimetric analysis. Filters were weighed both before and after sampling using a microbalance and were stored at $-4{ }^{\circ} \mathrm{C}$ after weighing.

\subsection{Sample analysis and quality control}

\subsubsection{Elemental analysis} with a flow rate of $1.0 \mathrm{ml} / \mathrm{min}$.

Teflon filters were detected by X-ray fluorescence (RIX3000, Rigaku Corp. Japan) for elemental analysis, including 9 crustal elements ( $\mathrm{Si}, \mathrm{Ti}, \mathrm{Al}, \mathrm{Mn}, \mathrm{Mg}, \mathrm{Ca}, \mathrm{Fe}$, $\mathrm{K}, \mathrm{Na}$ ) and 19 other trace elements (Cl, P, S, Sc, V, Cr, Co, Ni, Cu, Zn, As, Se, Br, Sr, $\mathrm{Cd}, \mathrm{Ba}, \mathrm{Pd}, \mathrm{Sn}, \mathrm{Sb})$.

\subsubsection{Ion analysis}

A quarter of each quartz filter was cut into a vessel then extracted three times with $5 \mathrm{ml}$ of ultrapure water using ultra-sonication and mechanical shaking in an ultrasonic cleaner at a frequency of $40 \mathrm{kHz}$ for $30 \mathrm{~min}$. The solution was then drawn into a syringe, filtered and injected into an ion chromatograph (DX-600, Dionex, USA)

\subsubsection{Carbon analysis}


Another quarter of each quartz filter was used for OC and EC analyses using a thermal/optical carbon analyser (DRI Model2001A, Atmoslytic, USA); the minimum detection limit for OC is $0.82 \mu \mathrm{gC} / \mathrm{cm}^{2}$, and $\mathrm{EC}$ is $0.2 \mu \mathrm{gC} / \mathrm{cm}^{2}$.

\subsubsection{PAH analysis}

For PAH analysis, gas chromatography (7890A, Agilent, USA) coupled to mass spectrometry (JMS-Q1000GC) (GC-MS) was used. The chromatographic column is a capillary column with a DB-5MS $(30 \mathrm{~m} \times 0.25 \mathrm{~mm} \times 0.25 \mu \mathrm{m})$, and the purity of the helium gas was $99.999 \%$ or higher. The filters were extracted via soxhlet extraction with n-hexane, dichloromethane and a PAHs purify solution. The extracting solution was concentrated using a rotary evaporator at $45^{\circ} \mathrm{C}$ and purified with a silica gel clean-up technique and then re-concentrated by rotary evaporation. Finally, the extracts were condensed to exactly $0.5 \mathrm{~mL}$ under eluting liquid nitrogen. The purified extracts were transferred into labelled sample bottles using a pipetter and stored in a refrigerator until analysis.

\subsubsection{Quality assurance $(Q A)$ and quality control $(Q C)$}

Sampling sites were chosen to be without fugitive dust or other pollution sources. Each filter was weighed 3 times before and after sampling, and the filter was packed with aluminium-foil and stored in a plastic container. The sampling impactor was cleaned by ethanol each time before sampling. Surgical masks and disposable gloves were worn when dealing with the filter to avoid any contamination of the samples.

For the chemical analysis, blank samples comprised $10 \%$ of the total test samples, and the detect value of the blank sample should be an order of magnitude lower than 
the detection limit. The relative standard deviation (RSD) for the ions were $0.085 \%$ for $\mathrm{NH}_{4}{ }^{+}, 0.88 \%$ for $\mathrm{NO}_{3}{ }^{-}$and $1.718 \%$ for $\mathrm{SO}_{4}{ }^{2-}$. For carbon analysis, a saccharose standard solution $(3.104 \mu \mathrm{gC} / \mu \mathrm{L})$ was used for calibration. One in every ten samples was repeated, and the precision was less than $3 \%$.

\section{Results and Discussion}

\subsection{Pollutant emissions in the iron and steel industry}

The description of the sampling sites and pollutant emission concentrations are provided in Table 1. Four different desulfurization technologies were chosen for the sintering process. The $\mathrm{SO}_{2}$ concentration after desulfurization varied between 94.29 and $277.14 \mathrm{mg} / \mathrm{m}^{3}$. Two plants exceeded the national emission standard of $200 \mathrm{mg} / \mathrm{m}^{3}$ for $\mathrm{SO}_{2}$. There are no special denitration facilities for sintering gas, and almost all of these plants meet the national standard of $300 \mathrm{mg} / \mathrm{m}^{3}$ for $\mathrm{NO}_{x}$, except for plant $\mathrm{A}$, which was $12 \mathrm{mg} / \mathrm{m}^{3}$ over the standard. The national standard for TSP is $30 \mathrm{mg} / \mathrm{m}^{3}$, where only plant A and plant E meet this requirement. The other plants need further efforts to avoid excessive emissions. The pelletizing process was only investigated in plant $\mathrm{B}$, and the high concentrations of $\mathrm{SO}_{2}\left(520 \mathrm{mg} / \mathrm{m}^{3}\right)$ found at this location are because of a desulfurization facility that is currently under construction. As for puddling and steelmaking processes, all the sampling sites are located after the secondary dedusting, and the blast gas was recycled after the primary dedusting.

Based on the emission parameters in Table 1 and the production data for these plants, the emission factors for each process can be calculated with the following equation, and the results are shown in Table 2. 


$$
k_{i}=\frac{C_{i} \times \mathrm{Q} \times 273.15}{P_{j} \times(273.15+\mathrm{T}) \times 10^{6}}
$$

197

where $k_{i}$ is the pollutant emission factor in $\mathrm{kg} / \mathrm{t} ; C_{i}$ is the average emitted pollutant concentration in $\mathrm{mg} / \mathrm{m}^{3}$; i indicates the type of pollutant; $\mathrm{Q}$ is the flue gas volume flow in $\mathrm{m}^{3} / \mathrm{h}$; T is the flue gas temperature in ${ }^{\circ} \mathrm{C} ; P_{j}$ is the average amount of product per unit time in $\mathrm{t} / \mathrm{h}$; and $\mathrm{j}$ indicates different production processes.

As shown in Table 2, the average emission factors for sintering, puddling and steelmaking processes were estimated. Similar to pervious research (Wu et al. 2015, Wang et al. 2016), the majority of acidic gaseous pollutants were discharged from the sintering process, while the calculated $\mathrm{SO}_{2}$ emission factor of this research at $0.62 \pm 0.004 \mathrm{~kg} / \mathrm{t}$ is much less than other data obtained before 2010, as compared in table 2, greatly can be caused by the desulfurization facilities, as for $\mathrm{NO}_{x}$ emission factors, the data at $0.62 \pm 0.003 \mathrm{~kg} / \mathrm{t}$ is quite the same with others, meaning the $\mathrm{NO}_{x}$ emission inventory is very stable under the no additional request for reduction, TSP and PM emission factors in this research are quite lower than others, which could also been contributed to de-dusting facilities, the direct $\mathrm{CO}_{2}$ emission factor for sintering flue gas is $280.6 \pm 65.5 \mathrm{~kg} / \mathrm{t}$, which is quite close to the value $(220 \sim 304 \mathrm{~kg} / \mathrm{t})$ calculated from the raw material consumption (Xu et al. 2016). Analogously, the TSP and PM emission factors for puddling and steelmaking process in this research are also lower than others due to the de-dusting facilities, these changes is typically obvious for these six plants selected are all under the strictest emission standards.

Sintering process is still the focus of pollution control for the whole manufacturing process. For the particulate matter, the TSP emission factor of the 
sintering process is 7 times higher than the puddling process and 40 times higher than the steelmaking process. The gap between these processes is smaller for the fine particles. When comparing the sintering and puddling processes, the $\mathrm{PM}_{10}$ and $\mathrm{PM}_{2.5}$ emission factors for the sintering process becomes 5 times and 4.5 times larger than the puddling process, respectively. For the sintering process, the emitted $\mathrm{PM}_{10}$ accounts for $37.8 \%$ of the TSP, and $\mathrm{PM}_{2.5}$ accounts for $27.14 \%$ of the TSP. For the puddling process, $\mathrm{PM}_{10}$ accounts for $52.3 \%$ of the TSP, and $\mathrm{PM}_{2.5}$ accounts for $38.1 \%$. For the steelmaking process, $\mathrm{PM}_{10}$ accounts for $38 \%$ of the TSP, and $\mathrm{PM}_{2.5}$ accounts for $24 \%$. Although the PM emission factor for the puddling process is not the highest among all of these processes, the proportion of the fine particles was the greatest.

\subsection{Particulate matter profiles of different manufacturing processes}

\subsubsection{The sintering process}

The sintering process was sampled and analysed for all six plants, and the PM chemical profiles are shown in Figure 2.

The PM has been sieved into three levels through the virtual impactor, including $\mathrm{PM}_{2.5}, \mathrm{PM}_{10}$ and $\mathrm{PM}_{>10}$. According to the elemental abundances in Figure 2, the identity of the elements of $\mathrm{PM}_{2.5}, \mathrm{PM}_{10}$ and $\mathrm{PM}_{>10}$ were consistent within the same plant, but the absolute values for the profiles were varied. For example, $\mathrm{Cl}$ increased with PM size for plant $\mathrm{D}$, while it decreased for plant E. In general, $\mathrm{SO}_{4}{ }^{2-}, \mathrm{NH}_{4}{ }^{+}$and OC tend to distribute in smaller particles, making fine particles much more harmful to human health and the climate (Li et al. 2014, Pablo-Romero et al. 2015). 
$\mathrm{SO}_{4}{ }^{2-}, \mathrm{NH}_{4}{ }^{+}$and $\mathrm{OC}$, while the relative abundance of these elements at each plant are

241 quite different. For plant $\mathrm{A}$, the content of $\mathrm{Ca}$ is close to $50 \%$ in $\mathrm{PM}_{2.5}$, and $\mathrm{SO}_{4}{ }^{2-}$

242 accounts for $10 \%$ of the total weight, showing the typical feature of calcium

243 desulphurization. $\mathrm{Cl}$ and $\mathrm{K}$ are mainly emitted from the raw sintering materials (Zhan

244 et al. 2013), so the $\mathrm{Cl}$ and $\mathrm{K}$ content of plants B-F are significant, which is in contrast

245 to plant $\mathrm{A}$ which has quite low $\mathrm{Cl}$ and $\mathrm{K}$ contents. These lower levels could be

246 indicative of pollutant control facilities, where the circulating fluidized bed

247 desulfurization coupled with a bag filter shows better performance for $\mathrm{Cl}$ adsorption.

248 For the anions, all six plants show high $\mathrm{SO}_{4}{ }^{2-}$ content, closely related to the high $\mathrm{SO}_{2}$

249 emissions of the sintering process. The $\mathrm{NH}_{4}{ }^{+}$content of plant $\mathrm{C}$ and plant $\mathrm{D}$ are

250 relatively high, especially plant $\mathrm{C}$ which has more $\mathrm{NH}_{3}$ added by ammonia

251 desulfurization. It can be inferred that PM profiles of the sintering process are greatly

252 impacted by pollutant control facilities. The desulfurizer and the dedusting processes

253 show an instant effect on the chemical compositions. Some harmful heavy metal

254 elements were also detected, such as $\mathrm{Pb}$ and $\mathrm{Sb}$. More effective and multi-functional

255 pollutant control technologies should be developed in order to reduce these harmful

256 components.

$257 \quad 3.2 .2$ The pelletizing process

258 Limited by the extensively used raw manufacturing process, the number and 259 scale of pellet firing machines in China is far less than the number of sintering 260 machines (Wang et al. 2016), so the pelletizing process was only investigated at one 261 site, plant $\mathrm{B}$. The chemical profiles of $\mathrm{PM}_{2.5}, \mathrm{PM}_{10}$ and $\mathrm{PM}_{>10}$ of pelletizing process 
are shown in Figure 3.

The identity of element emitted from the pelletizing process include $\mathrm{Al}, \mathrm{Si}, \mathrm{S}, \mathrm{Fe}$, $\mathrm{SO}_{4}{ }^{2-}$ and $\mathrm{NH}_{4}{ }^{+} . \mathrm{Fe}$ is the most abundant element of these components, and its content (38-65\%) increased with particle size. $\mathrm{SO}_{4}{ }^{2-}$ is the second highest element from the pelletizing process because of the high $\mathrm{SO}_{2}$ concentrations emitted; $\mathrm{SO}_{4}{ }^{2-}$ content decreased (36-14\%) in larger particles, showing similar changes as the sintering process. The pelletizing process shows low levels of OC content. This profile has not been compared because of the lack of other sampling locations. The pollutant emission standards for the pelletizing process are the same as the sintering process, so the chemical profiles of the pelletizing process will also be affected by pollutant control facilities.

\subsubsection{The puddling process}

Five puddling processes were sampled in plants B-F, and the PM profiles for the puddling process are shown in Figure 4.

The identity of elements in the puddling process is very simple, with the majority being Fe. All five plants show the same profiles; however, the Fe content varied from $59 \%$ to $91 \%$. Other components, such as $\mathrm{Ca}, \mathrm{Zn}, \mathrm{SO}_{4}{ }^{2-} \mathrm{OC}$ and $\mathrm{EC}$, were dispersed in these five profiles. The distinguishment between $\mathrm{PM}_{2.5}, \mathrm{PM}_{10}$ and $\mathrm{PM}_{>10}$ is slight, showing good consistency of these profiles.

\subsubsection{The steelmaking process}

Five steelmaking processes were sampled in plants A-D and plant F, and the PM profiles for the steelmaking process are shown in Figure 5. 

the puddling process, with $\mathrm{Fe}$ content varying from $47 \%$ to $78 \%$. Other components, such as $\mathrm{Si}, \mathrm{Ca}, \mathrm{Zn}, \mathrm{SO}_{4}{ }^{2-}$, exist concomitantly. $\mathrm{Ca}$ shows higher content (24-34\%) in plant $\mathrm{D}$, which might be related to the raw materials. The differences between $\mathrm{PM}_{2.5}$,

$\mathrm{PM}_{10}$ and $\mathrm{PM}_{>10}$ are mainly the $\mathrm{Fe}$ concentration. Fe content decreased in larger showed irregular changes in Fe.

\subsection{Comparison of $P M_{2.5}$ and $P M_{10}$ for the different processes} average algorithm based on the amount PM emissions was proposed, and the formula is as follows:

$$
\propto_{\mathrm{i}, \mathrm{j}, \mathrm{n}}=\frac{C_{i, j, n} Q_{j, n} \times \frac{273.15}{\left(273.15+\mathrm{T}_{\mathrm{j}, \mathrm{n}}\right)}}{\sum_{\mathrm{n}=1}^{\mathrm{n}} C_{i, j, n} Q_{j, n} \times \frac{273.15}{\left(273.15+\mathrm{T}_{\mathrm{j}, \mathrm{n}}\right)}}
$$

where $\alpha$ is the coefficient of the weighted average; i represents the type of pollutant;

297 Q is the flue gas volume flow, in $\mathrm{m}^{3} / \mathrm{h}$; $\mathrm{T}$ is the flue gas temperature in ${ }^{\circ} \mathrm{C} ; \mathrm{j}$ represents 298 a different production process; and $\mathrm{n}$ represents the number of the plant. in plant $\mathrm{A}$ is marked as $\alpha_{\mathrm{PM} 2.5, \text { Sintering, } \mathrm{A}}=0.0093$. plant PM profile and the weighted average coefficients as below.

$$
F_{\mathrm{i}, \mathrm{j}, \mathrm{k}}=\frac{\sum_{\mathrm{n}=1}^{\mathrm{n}} \propto_{i, j, n} \times \mathrm{F}_{\mathrm{i}, \mathrm{j}, \mathrm{k}}}{\mathrm{n}}
$$


where $\mathrm{F}$ is the calculated profile value; i represents the type of pollutant; $\mathrm{j}$ represents a different production process; $\mathrm{n}$ represents the number of the plant; and $\mathrm{k}$ represents the chemical species or element.

The average profile of $\mathrm{Si}$ in $\mathrm{PM}_{2.5}$ emitted in the sintering process is marked and calculated as $F_{\mathrm{PM} 2.5, \text { Sintering,Si }}=0.1464 \pm 0.0115$. The profiles are displayed in Table 3 .

According to the data in Table 3, the chemical species can be divided into crustal matter ( $\mathrm{Si}, \mathrm{Ti}, \mathrm{Sl}, \mathrm{Mn}, \mathrm{Mg}, \mathrm{Ca}, \mathrm{Fe}, \mathrm{K}, \mathrm{Na}$ ), trace species (Cl, P, Sc, S, V, Cr, Co, Ni, $\mathrm{Cu}, \mathrm{Zn}, \mathrm{As}, \mathrm{Se}, \mathrm{Br}, \mathrm{Sr}, \mathrm{Cd}, \mathrm{Ba}, \mathrm{Pd}, \mathrm{Sn}, \mathrm{Sb}$ ), nitrate, sulfate, ammonium, organic matter, elemental carbon and others, one point should be mentioned is that the $S$ in trace species is rest $S$ of the total $S$ subtract $S$ in sulphate to avoid the overlap calculation. These eight categories of $\mathrm{PM}_{2.5}$ and $\mathrm{PM}_{10}$ profiles are graphically shown in Figure 6.

Crustal matter, trace species and sulfate are the main components of $\mathrm{PM}_{2.5}$ and $\mathrm{PM}_{10}$ in iron and steel plants. Sulfate and OC tend to distribute into smaller particles $\left(\mathrm{PM}_{2.5}\right)$. Larger particles $\left(\mathrm{PM}_{10}\right)$ are mainly composites of crustal matter and trace species. For the sintering process, crustal matter and trace species account for $35 \%$ and $32 \%$ of the $\mathrm{PM}_{2.5}$ respectively; sulfate accounts for $13 \%$, nitrate accounts for $8.9 \%$ and $\mathrm{OC}$ accounts for $6 \%$. The distribution of components in the sintering process is more complex than the other processes. The high sulfate content of the pelletizing process indicates an urgent need for desulfurization. Crustal matter became the main composition in the puddling and steelmaking processes.

Aiming to identify the distinguishing features and similarities in the PM profiles, 
the coefficient of divergence $(\mathrm{CD})$, a self-normalizing parameter used to measure the spread of the data points for two datasets (Kong et al. 2011), was calculated as follows:

$$
C D_{j k}=\sqrt{\frac{1}{P} \sum_{i}^{p}\left(\frac{x_{i j}-x_{i k}}{x_{i j}+x_{i k}}\right)^{2}}
$$

where $\mathrm{j}$ and $\mathrm{k}$ indicate the two different PM profiles; $P$ is the number of components; and $x_{i j}$ shows the relative concentration of chemical species $i$ in profile $j$. If the CD value close to 0 , the PM profiles are almost the same. If CD approaches zero, source $\mathrm{i}$ and $\mathrm{k}$ are similar. If the $\mathrm{CD}$ value approaches one, the two profiles are significantly different (Wongphatarakul et al. 1998, Han et al. 2010). A CD value of 0.3 was adopted as a demarcation, where $\mathrm{CD}<0.3$ means the two profiles are similar, and $\mathrm{CD}>0.3$ means the two profiles are different.

CD parameters were initially used to compare the divergence between $\mathrm{PM}_{2.5}$ and $\mathrm{PM}_{10}$ for same process. The results are shown in Figure 7.

$\mathrm{PM}_{2.5}$ and $\mathrm{PM}_{10}$ profiles for the same process are similar to each other, with $\mathrm{CD}$ values ranging from 0.1697 to 0.2578 (Figure 7), so $\mathrm{PM}_{2.5}$ was chosen for the comparison of different processes. The results are shown in Figure 8.

From Figure 8, $\mathrm{PM}_{2.5}$ profiles of the four process were different from each other, with $\mathrm{CD}$ values ranging from 0.4802 to 0.7500 . In the sintering process, the $\mathrm{CD}$ values, compared to other processes, are all over 0.6 , showing the same conclusions as above.

Furthermore, the differences between the $\mathrm{PM}_{2.5}$ profiles of these processes will directly cause uncertainty in the entire iron and steel industry profile. These factors 
make it difficult to infer the entire iron and steel industry profiles with insufficient data, showing this topic still needs work to continuously update PM profiles in China.

\subsection{PAH analysis of particulate matter}

PAHs are formed by incomplete combustion and pyrolysis of organic materials (Ravindra et al. 2008). Sixteen PAHs listed by the US EPA were measured in this study: 12 samples from sintering, pelletizing, puddling and steelmaking processes have been analysed, and the results are shown in Figure 9.

One point should be mentioned regarding Figure 9; the ranges of the Y-axes are quite different among the four processes. The total $\mathrm{PAH}$ concentration in $\mathrm{PM}_{2.5}$ resulting from the sintering process reaches $73.28 \pm 0.73 \mu \mathrm{g} / \mathrm{m}^{3}$, while the value for the pelletizing process is only $0.026 \pm 0.0007 \mu \mathrm{g} / \mathrm{m}^{3}$. PAHs in the puddling and steelmaking processes reach $0.054 \pm 0.0008 \mu \mathrm{g} / \mathrm{m}^{3}$ and $0.054 \pm 0.0016 \mu \mathrm{g} / \mathrm{m}^{3}$, respectively. Most of the PAHs in PM are sourced from the sintering process, according the flue gas volume and the sintering production, the emission factor of the total PAHs is calculated at around $0.273 \pm 0.0027 \mathrm{~g} / \mathrm{t}$.

The PAHs in PM for the pelletizing, puddling and steelmaking processes are mainly NaP, Acy, Phe, Flu, Pyr, BaA and Chr. These PAH compounds have less than four benzene rings. PAHs from the sintering process mainly include 4 benzene ring PAHs, such as Flu, Pyr, BaA and Chr, and 5 and 6 benzene rings PAHs, such as DBA and BghiP, which might be pyrolysed from the raw materials.

The equivalent toxicity of PAHs was calculated using BaPE (Fang et al. 2004). $\mathrm{BaPE}=\mathrm{BaA} \times 0.06+\mathrm{B}[\mathrm{b}, \mathrm{k}] \mathrm{F} \times 0.07+\mathrm{BaP}+\mathrm{DBA} \times 0.6+\mathrm{IND} \times 0.08$. The $\mathrm{BaPE}$ value of 
$\mathrm{PM}_{2.5}$ for the sintering process in this study is $9.92 \mu \mathrm{g} / \mathrm{m}^{3}, 37.6 \%$ lower than the value reported by Kong et al. obtained in $2010\left(13.65 \mu \mathrm{g} / \mathrm{m}^{3}\right)$ (Kong et al. 2013), which might be affected by the raw materials and the manufacturing processes, however the PAHs components distribution for two work is similar, the majority of PAHs are over four benzene rings, indicating the PAHs in sintering PM are mainly caused by the high temperature cracking of the fossil fuels. So in order to reduce the PAHs emission intensity in the fine particles, pollutants control facilities and the raw material substitution technology should be enforced in China.

\section{Conclusions}

Source-level sampling method was adopted in this study sampled six iron and steel plants and four main manufacturing processes with over 150 samples were collected and measured in this study. The emission factors of $\mathrm{CO}_{2}, \mathrm{CO}, \mathrm{SO}_{2}, \mathrm{NO}_{x}$, TSP, $\mathrm{PM}_{2.5}$ and $\mathrm{PM}_{10}$ in the sintering flue gas are the highest among all the processes, demonstrating the urgency of sintering flue gas purification.

The three PM sizes were divided for chemical profiles, and the identity of elements in $\mathrm{PM}_{2.5}, \mathrm{PM}_{10}$ and $\mathrm{PM}_{>10}$ are consistent within the same plant. The absolute values for the profiles are varied; $\mathrm{SO}_{4}{ }^{2-}, \mathrm{NH}_{4}{ }^{+}$and $\mathrm{OC}$ tend to distribute into the smaller particles. The elements in PM emitted from the sintering process include $\mathrm{Ca}$,

$\mathrm{Cl}, \mathrm{K}, \mathrm{SO}_{4}{ }^{2-}, \mathrm{NH}_{4}{ }^{+}$and $\mathrm{OC}$, and the mass percentage of these elements is greatly impacted by the pollutant control facilities. The elements emitted from the pelletizing process mainly include $\mathrm{Al}, \mathrm{Si}, \mathrm{S}, \mathrm{Fe}, \mathrm{SO}_{4}{ }^{2-}$ and $\mathrm{NH}_{4}{ }^{+}$. The lack of desulfurization facility causes $\mathrm{SO}_{4}{ }^{2-}$ to be the second highest for this process. $\mathrm{Fe}$ is the main element 
392

393

in both the puddling and steelmaking processes, with the content varying from $47 \%$ to $91 \%$.

The coefficient of divergence was calculated to compare the differences between $\mathrm{PM}$ profiles. The divergence between $\mathrm{PM}_{2.5}$ and $\mathrm{PM}_{10}$ with same process is ambiguous, with $\mathrm{CD}$ values ranging from 0.1697 to 0.2578 . The $\mathrm{PM}_{2.5}$ profiles of the four process were quite different from each other, with $\mathrm{CD}$ values ranging from 0.4802 to 0.7500 . It is notably difficult to determine the entire iron and steel industry profiles because of insufficient data, so more efforts will be required to update the PM profiles in China. Because of this work is established on the source-level sampling method, the PM condensation part from the flue gas should be added for source appointment.

PAHs from the four process were also investigated, and most of the PAHs in PM are sourced from the sintering process, the majority of PAHs are over four benzene rings, indicating the PAHs in sintering PM are mainly caused by the high temperature cracking of the fossil fuels. The total $\mathrm{PAH}$ concentration in $\mathrm{PM}_{2.5}$ from the sintering process is $73.28 \pm 1.45 \mu \mathrm{g} / \mathrm{m}^{3}$, with the BaPE value calculated at $9.92 \mu \mathrm{g} / \mathrm{m}^{3}, 37.6 \%$ lower than the data obtained in 2010, showing the pollutants control facilities perform synergic remove effect on PAHs emission intensities.

\section{Acknowledgments}

This research was financially supported by the key research program of the Chinese Academy of Sciences (XDB05010100) and the National Science Foundation 
413 of China (No.21547013 and No.51608508). 


\section{References}

China environmental stastatical yearbook of 2014, Ministry of the enviromental protection of the people's republic of China, Beijing, 2016.

Emission standard of air pollutants for sintering and pelletizing of iron and steel industry. Beijing, Ministry of enviromental protection of the people's republic of China. GB 28662-2012.

Ai, W., Laycock, R. G., Rappleye, D. S., Fletcher, T. H. and Bons, J. P., 2011. Effect of particle size and trench configuration on deposition from fine coal flyash near film cooling holes. Energy \& Fuels 25(3): 1066-1076.

Amodio, M., Andriani, E., Dambruoso, P. R., de Gennaro, G., Di Gilio, A., Intini, M., Palmisani, J. and Tutino, M., 2013. A monitoring strategy to assess the fugitive emission from a steel plant. Atmospheric Environment 79: 455-461.

Chen, G., Liu, J., Huangfu, Y., Wang, H., Shi, G., Tian, Y., Zhu, Y. and Li, J., 2016. Seasonal variations and source apportionment of ambient $\mathrm{PM}_{10}$ and $\mathrm{PM}_{2.5}$ at urban area of Hefei. China Environmental Science 36(07): 1938-1946.

Ciuta, S., Schiavon, M., Chistè, A.,Ragazzi, M., Rada, E.C., Tubino, M., Badea, A., Apostol, T., 2012. Role offeedstock transport in the balance of primary PM emissions in two case-studies:RMSW incineration vs. sintering plant. UPB Scientific Bulletin 74(1): 211-218.

Elena, C. R., Marco, L., Federico, T., Marco, R. and Barbara, R., 2016. Characterization of fine and ultrafine particles in air near a steel making plant: an Italian case. Management of Environmental Quality: An International Journal 27(4): 350-363.

Fang, G. C., Chang, C. N., Wu, Y. S., Fu, P. P. C., Yang, I. L. and Chen, M. H., 2004. Characterization, identification of ambient air and road dust polycyclic aromatic hydrocarbons in central Taiwan, Taichung. Science of the Total Environment 327(1-3): 135-146.

Han, B., Kong, S. F., Bai, Z. P., Du, G., Bi, T., Li, X., Shi, G. L. and Hu, Y., 2010. Characterization of elemental species in $\mathrm{PM}_{2.5}$ samples collected in four cities of northeast China. Water Air and Soil Pollution 209(1-4): 15-28.

Ho, K. F., Lee, S. C., Chow, J. C. and Watson, J. G., 2003. Characterization of $\mathrm{PM}_{10}$ and $\mathrm{PM}_{2.5}$ source profiles for fugitive dust in Hong Kong. Atmospheric Environment 37(8): 1023-1032.

Jiang, J., Deng, J. and Duan, L., 2014. Development of two stage virtual impactor for stationary source $\mathrm{PM}_{10}$ and $\mathrm{PM}_{2.5}$ sampling. Environmental Science 35(10): 3639-3643.

Kong, S., Ji, Y., Lu, B., Chen, L., Han, B., Li, Z. and Bai, Z., 2011. Characterization of PM $_{10}$ source profiles for fugitive dust in Fushun-a city famous for coal. Atmospheric Environment 45(30): 5351-5365.

Kong, S., Ji, Y., Lu, B., Zhao, X., Han, B. and Bai, Z., 2014. Similarities and Differences in $\mathrm{PM}_{2.5}$, $\mathrm{PM}_{10}$ and TSP Chemical Profiles of Fugitive Dust Sources in a Coastal Oilfield City in China. Aerosol and Air Quality Research 14(7): 2017-U2291.

Kong, S. F., Ji, Y. Q., Li, Z. Y., Lu, B. and Bai, Z. P., 2013. Emission and profile characteristic of polycyclic aromatic hydrocarbons in $\mathrm{PM}_{2.5}$ and $\mathrm{PM}_{10}$ from stationary sources based on dilution sampling. Atmospheric Environment 77: 155-165.

Li, J., Zhu, M., Zhang, Z., Zhang, K., Shen, G. and Zhang, D., 2016. The mineralogy, morphology and sintering characteristics of ash deposits on a probe at different temperatures during combustion of blends of Zhundong lignite and a bituminous coal in a drop tube furnace. Fuel Processing 
Technology 149: 176-186.

Li, T., Chen, X. and Yan, Z., 2013. Comparison of fine particles emissions of light-duty gasoline vehicles from chassis dynamometer tests and on-road measurements. Atmospheric Environment 68: 82-91.

Li, Y., Schwandner, F. M., Sewell, H. J., Zivkovich, A., Tigges, M., Raja, S., Holcomb, S., Molenar, J. V., Sherman, L., Archuleta, C., Lee, T. and Collett, J. L., Jr., 2014. Observations of ammonia, nitric acid, and fine particles in a production region. Atmospheric Environment 83: 80-89.

Liu, Z. R., Hu, B., Liu, Q., Sun, Y. and Wang, Y. S., 2014. Source apportionment of urban fine particle number concentration during summertime in Beijing. Atmospheric Environment 96: 359-369.

Ma, Y., Zhu, M. and Zhang, D., 2015. Effect of the molecular structures of biodiesel on emission characteristics of diesel combustion in a compression ignition engine. 10th Asia-Pacific Conference on Combustion, ASPACC 2015, July 19, 2015 - July 22, 2015, Beijing, China, Combustion Institute.

Ma, Z., Deng, J., Li, Z., Li, Q., Zhao, P., Wang, L., Sun, Y., Zheng, H., Pan, L., Zhao, S., Jiang, J., Wang, S. and Duan, L., 2016. Characteristics of $\mathrm{NO}_{\mathrm{x}}$ emission from Chinese coal-fired power plants equipped with new technologies. Atmospheric Environment 131: 164-170.

Nielsen, M. T., Livbjerg, H., Fogh, C. L., Jensen, J. N., Simonsen, P., Lund, C., Poulsen, K. and Sander, B., 2002. Formation and emission of fine particles from two coal-fired power plants. Combustion Science and Technology 174(2): 79-113.

Pablo-Romero, M. d. P., Roman, R., Gonzalez Limon, J. M. and Praena-Crespo, M., 2015. Effects of fine particles on children's hospital admissions for respiratory health in Seville, Spain. Journal of the Air \& Waste Management Association 65(4): 436-444.

Raman, R. S. and Hopke, P. K., 2007. Source apportionment of fine particles utilizing partially speciated carbonaceous aerosol data at two rural locations in New York State. Atmospheric Environment 41(36): 7923-7939.

Ravindra, K., Sokhi, R. and Van Grieken, R., 2008. Atmospheric polycyclic aromatic hydrocarbons: Source attribution, emission factors and regulation. Atmospheric Environment 42(13): 2895-2921.

Sahanavin, N., Tantrakarnapa, K.,Prueksasit, T., 2016. Ambient $\mathrm{PM}_{10}$ and $\mathrm{PM}_{2.5}$ concentrations at different high traffic-related street configurations in Bangkok, Thailand. The Southeast Asian journal of tropical medicine and public health 47(3): 528-535.

Simon, H., Beck, L., Bhave, P. V., Divita, F., Hsu, Y., Luecken, D., Mobley, J. D., Pouliot, G. A., Reff, A., Sarwar, G. and Strum, M., 2010. The development and uses of EPA's SPECIATE database. Atmospheric Pollution Research 1(4): 196-206.

Stroe, C. C., Panaitescu, V. N., Ragazzi, M., Rada, E. C. and Ionescu, G., 2014. Some considerations on the environmentalimpact of highway traffic. Revista de Chimie 65(2): 152-155.

Wada, M., Tsukada, M., Namiki, N., Szymanski, W. W., Noda, N., Makino, H., Kanaoka, C. and Kamiya, H., 2016. A two-stage virtual impactor for in-stack sampling of $\mathrm{PM}_{2.5}$ and $\mathrm{PM}_{10}$ in flue gas of stationary sources. Aerosol and Air Quality Research 16(1): 36-45.

Wang, H., Pei, Y., Zhang, C. and Zhao, Z., 2016. Green development of sintering/pellet procedure in China iron and steel industry. Iron and Steel 51(1): 1-7.

Wang, K., Tian, H. Z., Hua, S. B., Zhu, C. Y., Gao, J. J., Xue, Y. F., Hao, J. M., Wang, Y. and Zhou, J. R., 2016. A comprehensive emission inventory of multiple air pollutants from iron and steel industry in China: Temporal trends and spatial variation characteristics. Science of the Total Environment 559: 7-14. 
Wongphatarakul, V., Friedlander, S. K. and Pinto, J. P., 1998. A comparative study of PM $_{2.5}$ ambient aerosol chemical databases. Environmental Science \& Technology 32(24): 3926-3934.

Wu, B., Shen, X., Cao, X., Zhang, W., Wu, H. and Yao, Z., 2015. Carbonaceous composition of $\mathrm{PM}_{2.5}$ emitted from on-road China III diesel trucks in Beijing, China. Atmospheric Environment 116: 216-224.

Wu, X. C., Zhao, L. J., Zhang, Y. X., Zheng, C. H., Gao, X. and Cen, K. F., 2015. Primary Air Pollutant Emissions and Future Prediction of Iron and Steel Industry in China. Aerosol and Air Quality Research 15(4): 1422-1432.

Xu, W., Wan, B., Zhu, T. and Shao, M., 2016. $\mathrm{CO}_{2}$ emissions from China's iron and steel industry. Journal of Cleaner Production 139: 1504-1511.

Xu, Y. and Zhou, Q., 2012. Emission characteristics and spatial distribution of road fugitive dust in Tianjin. China Environmental Science 32(12): 2168-2173.

Yang, H.-H., 2015. Emission Characteristics and Chemical Compositions of both Filterable and Condensable Fine Particulate from Steel Plants. Aerosol and Air Quality Research 15(4).

Yang, H. H., Lai, S. O., Hsieh, L. T., Hsueh, H. J. and Chi, T. W., 2002. Profiles of PAH emission from steel and iron industries. Chemosphere 48(10): 1061-1074.

Yi, H. H., Hao, J. M., Duan, L., Li, X. H. and Guo, X. M., 2006. Characteristics of inhalable particulate matter concentration and size distribution from power plants in China. Journal of the Air \& Waste Management Association 56(9): 1243-1251.

Zhan, G. and Guo, Z. C., 2013. Basic properties of sintering dust from iron and steel plant and potassium recovery. Journal of Environmental Sciences 25(6): 1226-1234.

Zhang, Y., Wang, W., Wu, S., Wang, K., Minoura, H. and Wang, Z., 2014. Impacts of updated emission inventories on source apportionment of fine particle and ozone over the southeastern US. Atmospheric Environment 88: 133-154.

Zhao, Z. F., Du, Q., Zhao, G. B., Gao, J. M., Dong, H. M., Cao, Y., Han, Q., Yuan, P. F. and Su, L. P., 2014. Fine particle emission from an industrial coal-fired circulating fluidized-bed boiler equipped with a fabric filter in China. Energy \& Fuels 28(7): 4769-4780.

Zheng, M., Zhang, Y., Yan, C., Fu, H. and Niu, H., 2013. Establishing PM 2.5 industrial source profiles in Shanghai. China Environmental Science 33(8): 1354-1359. 


\section{Figure captions}

Figure 1. Schematic of sampling sites for the sintering process

Figure 2. PM chemical profiles for the sintering process

Figure 3. PM chemical profiles for the pelletizing process

Figure 4. PM chemical profiles for the puddling process

Figure 5. PM chemical profiles for the steelmaking process

Figure 6. $\mathrm{PM}_{2.5}$ and $\mathrm{PM}_{10}$ profiles for the different processes

Figure 7. The coefficient of divergence between $\mathrm{PM}_{2.5}$ and $\mathrm{PM}_{10}$ for the different processes

Figure 8. The coefficient of divergence between the different processes for $\mathrm{PM}_{2.5}$

Figure 9. PAH mass concentrations in PM emitted from various processes 


\section{Figure 1}

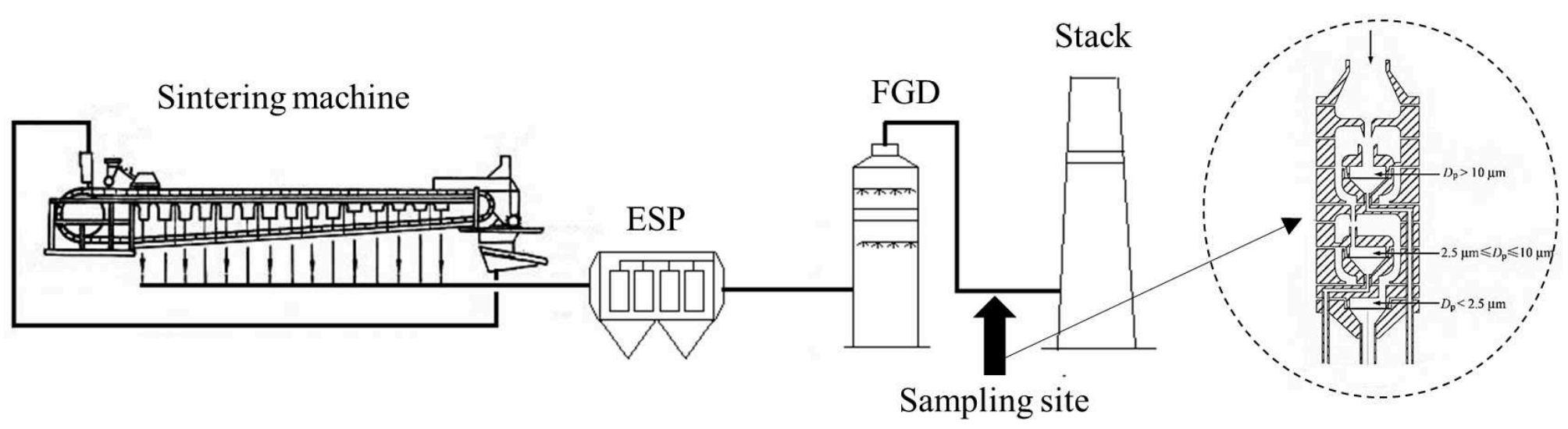


Figure 2

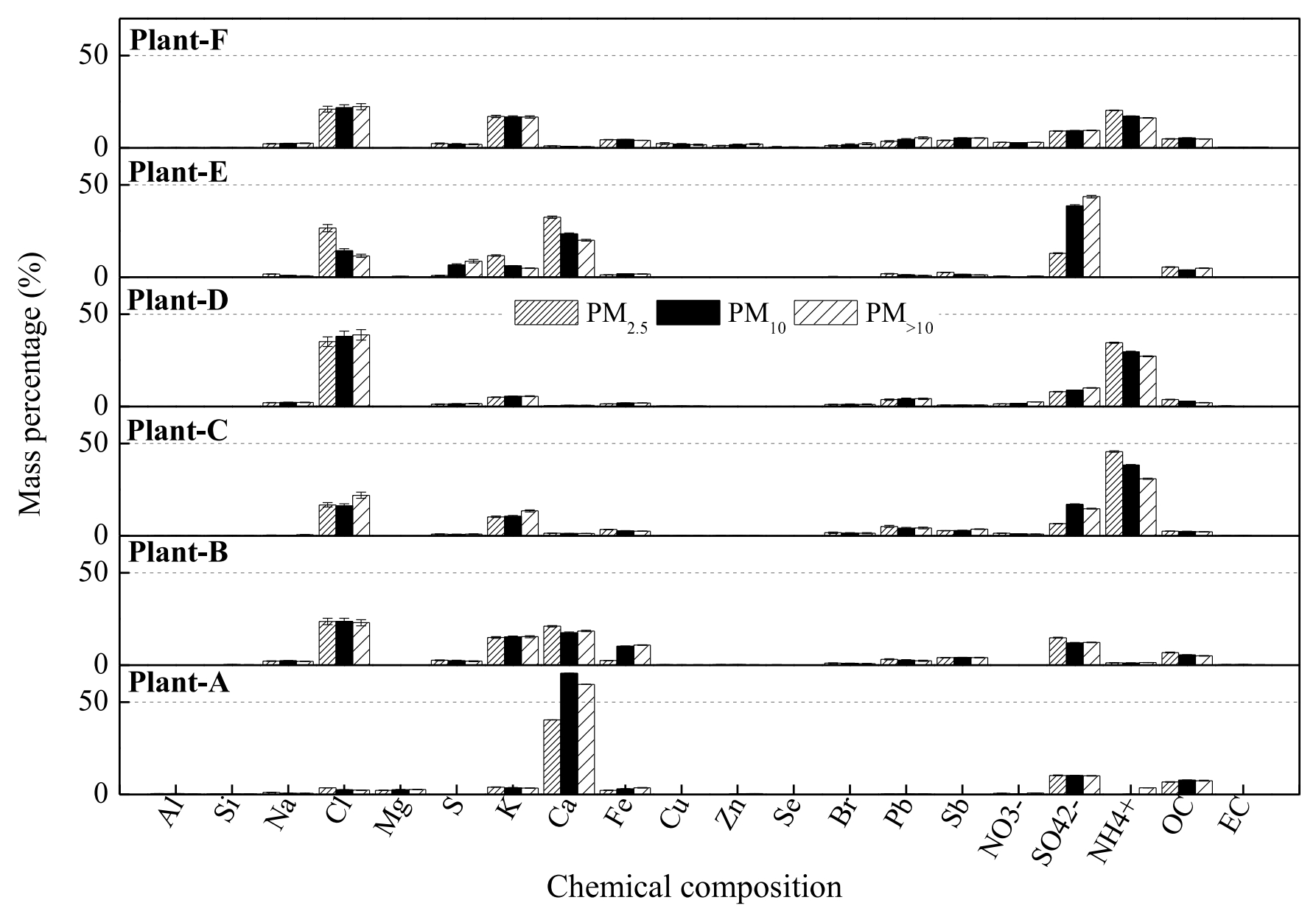


Figure 3

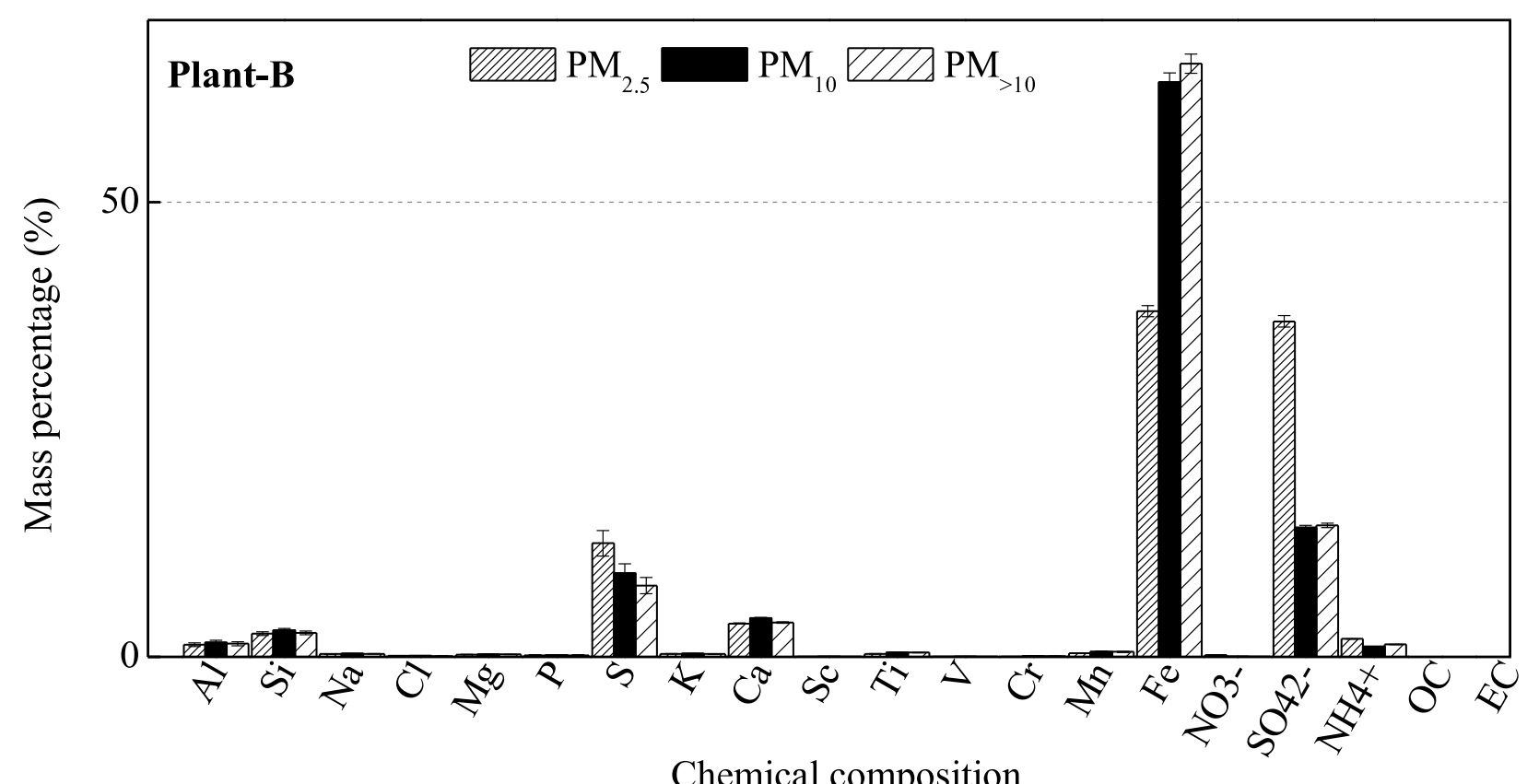

Chemical composition 
Figure 4

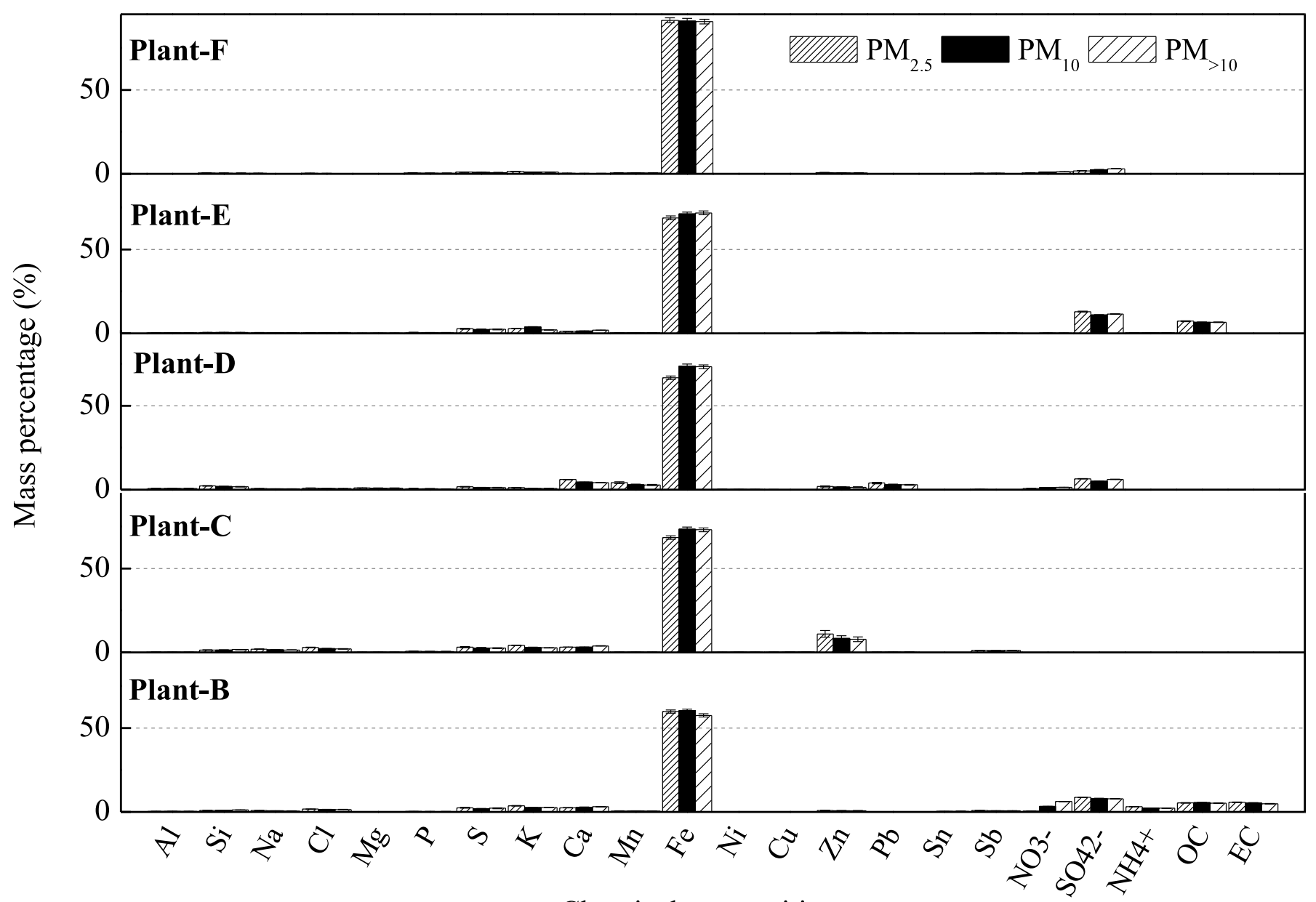

Chemical composition 


\section{Figure 5}

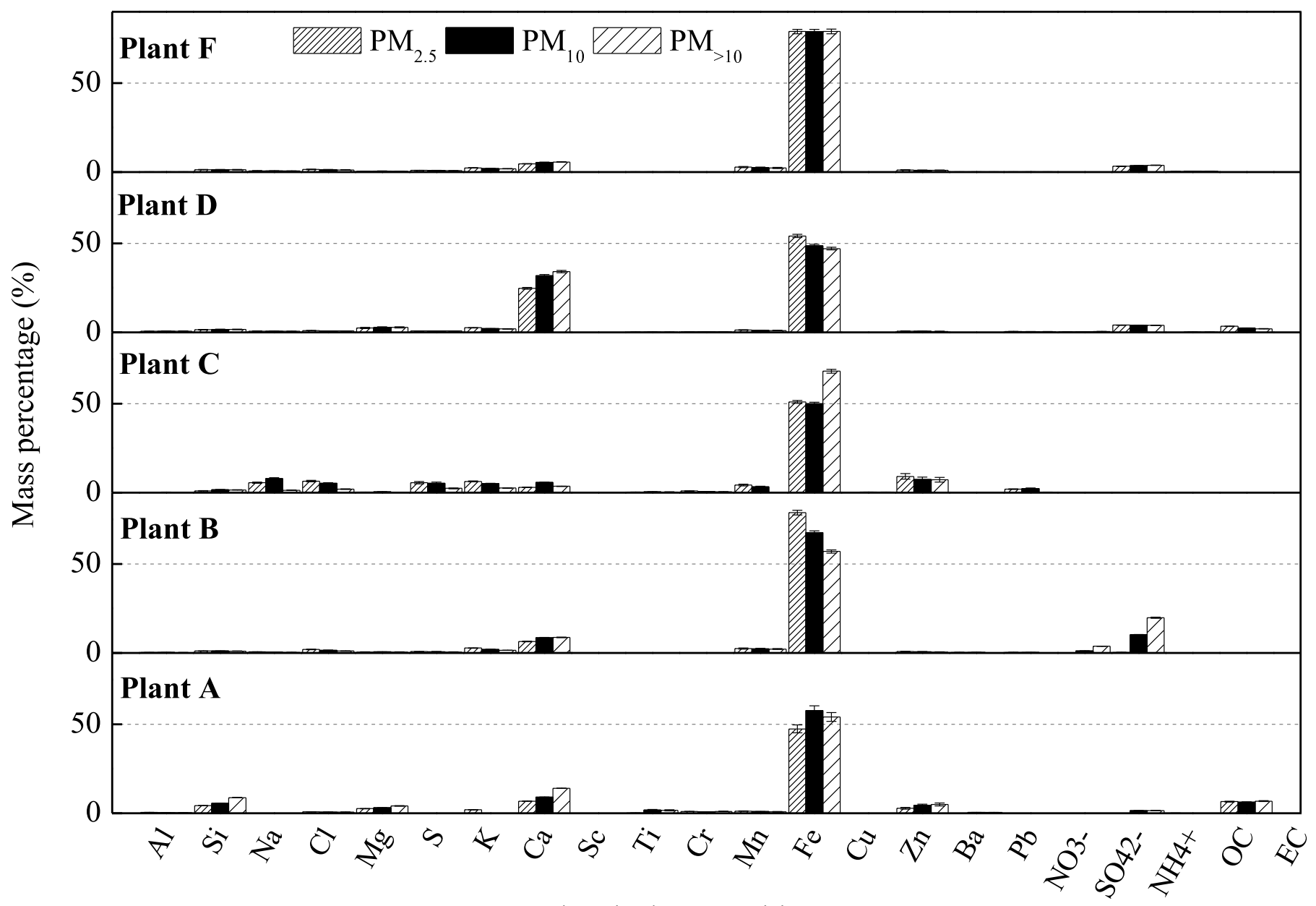

Chemical composition 
Figure 6

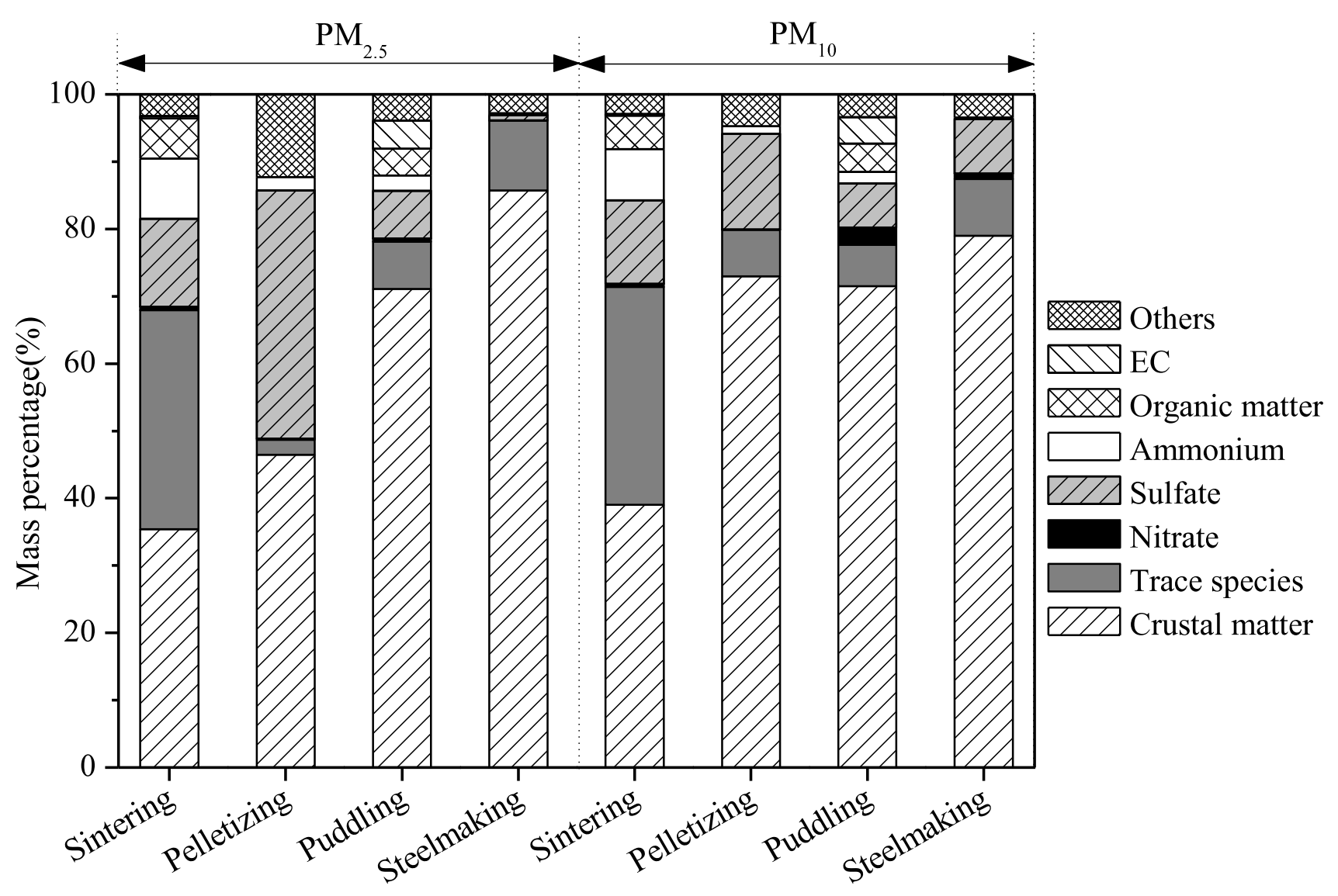


Figure 7
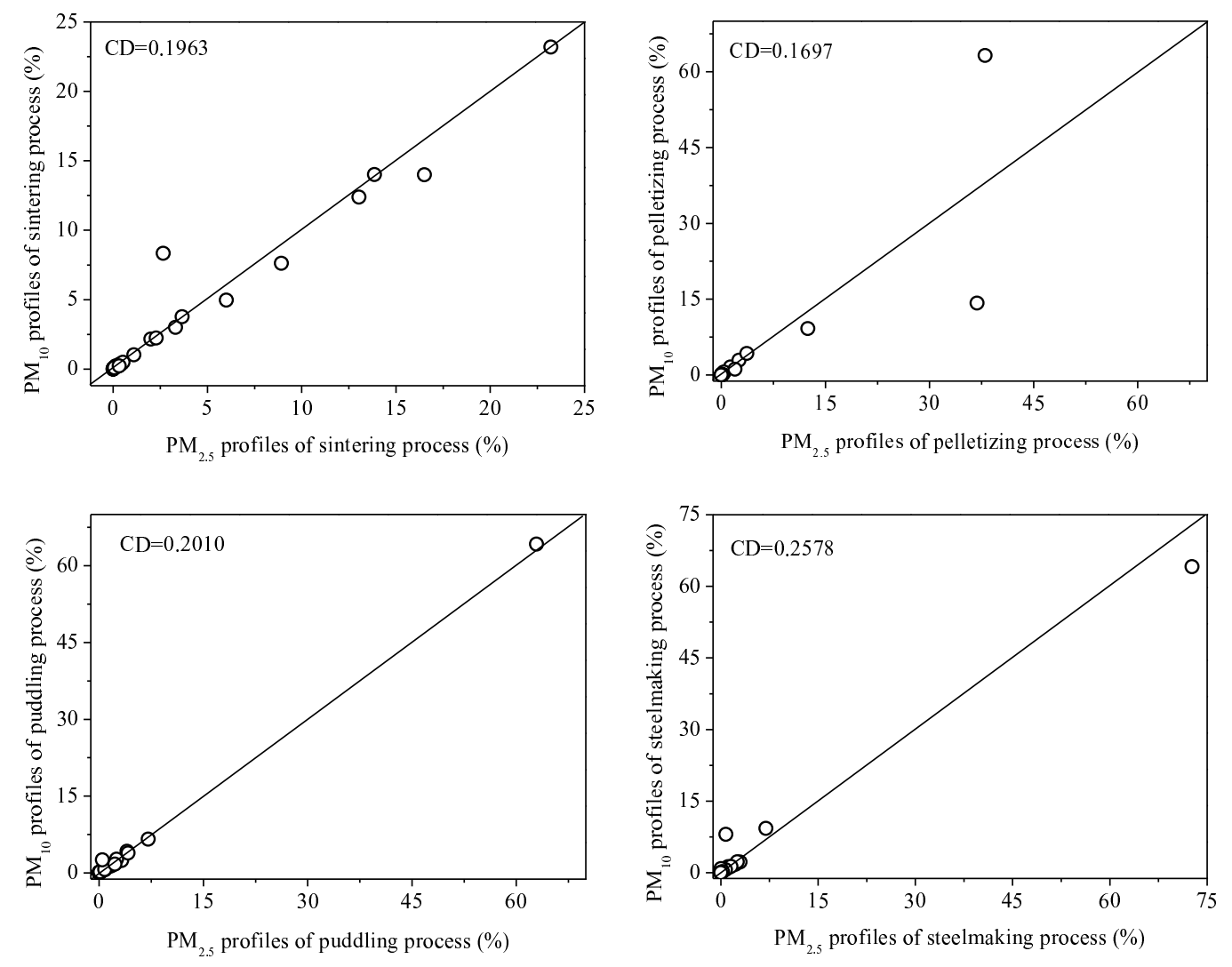
Figure 8
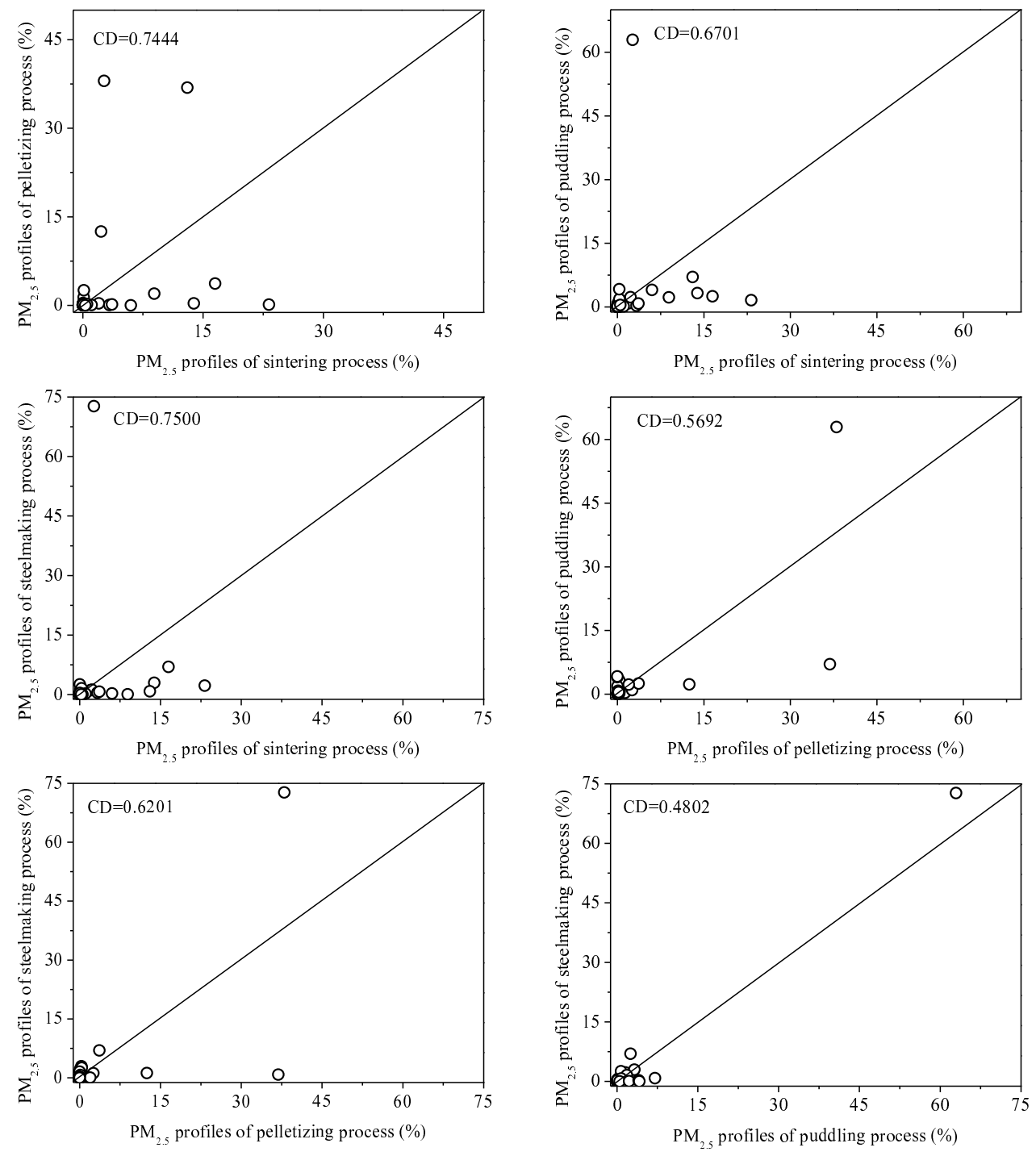
Figure 9

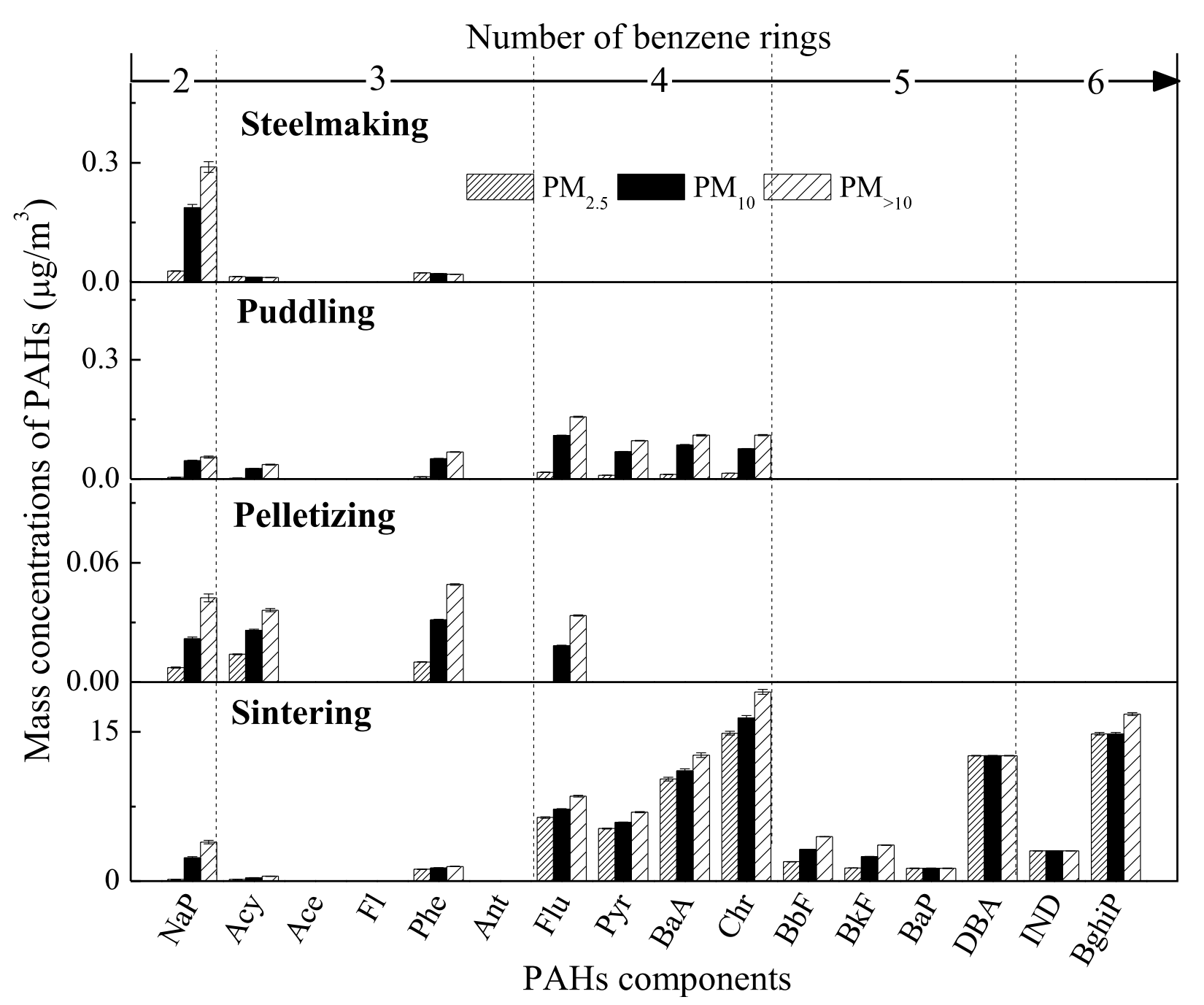


Table 1. Sampling sites description and flue gas parameters

\begin{tabular}{|c|c|c|c|c|c|c|c|c|c|c|c|c|}
\hline $\begin{array}{l}\text { Plant } \\
\text { No. }\end{array}$ & Process & $\begin{array}{l}\text { Collection } \\
\text { location }\end{array}$ & $\mathrm{O}_{2}(\%)$ & $\begin{array}{l}\mathrm{CO}_{2} \\
(\%)\end{array}$ & $\begin{array}{c}\mathrm{CO} \\
\left(\mathrm{mg} / \mathrm{m}^{3}\right)\end{array}$ & $\begin{array}{c}\mathrm{SO}_{2} \\
\left(\mathrm{mg} / \mathrm{m}^{3}\right)\end{array}$ & $\begin{array}{c}\mathrm{NO}_{\mathrm{x}} \\
\left(\mathrm{mg} / \mathrm{m}^{3}\right)\end{array}$ & $\begin{array}{c}\text { TSP } \\
\left(\mathrm{mg} / \mathrm{m}^{3}\right)\end{array}$ & $\begin{array}{c}\mathrm{PM}_{10} \\
\left(\mathrm{mg} / \mathrm{m}^{3}\right)\end{array}$ & $\begin{array}{c}\mathrm{PM}_{2.5} \\
\left(\mathrm{mg} / \mathrm{m}^{3}\right)\end{array}$ & $\begin{array}{c}\mathrm{T} \\
\left({ }^{\circ} \mathrm{C}\right)\end{array}$ & $\begin{array}{c}\mathrm{Q} \\
\left(\mathrm{m}^{3} / \mathrm{h}\right)\end{array}$ \\
\hline \multirow[t]{2}{*}{ A } & Sintering & $\begin{array}{l}\text { Stack after ESP } \\
\text { and CFB-FGD }\end{array}$ & 16.27 & 3.81 & 293.75 & 277.14 & 312 & 3.9 & 1.394 & 0.946 & 68 & $64.92 \times 10^{4}$ \\
\hline & Steelmaking & Stack after BF & 20.88 & 0 & 13.75 & 0 & 0 & 0.5 & 0.273 & 0.227 & 56 & $47.98 \times 10^{4}$ \\
\hline \multirow{4}{*}{ B } & Sintering & $\begin{array}{l}\text { Stack after ESP } \\
\text { and L-WFGD }\end{array}$ & 15.42 & 4.52 & 6987.5 & 94.29 & 144.64 & 121.41 & 73.89 & 58.7 & 59 & $85.15 \times 10^{4}$ \\
\hline & Pelletizing & Stack after ESP & 17.19 & 3.34 & 10 & 520 & 79.02 & 10.01 & 1.32 & 0.57 & 125 & $59.19 \times 10^{4}$ \\
\hline & Puddling & Stack after BF & 20.92 & 0 & 51.25 & 14.29 & 0 & 8.25 & 0.69 & 0.38 & 56 & $42.39 \times 10^{4}$ \\
\hline & Steelmaking & Stack after BF & 20.78 & 0 & 98.75 & 0 & 0 & 1.78 & 0.36 & 0.24 & 54 & $47.18 \times 10^{4}$ \\
\hline \multirow{3}{*}{$\mathrm{C}$} & Sintering & $\begin{array}{l}\text { Stack after ESP } \\
\text { and A-WFGD }\end{array}$ & 15.88 & 6.12 & 6983 & 136 & 131 & 37.56 & 11.32 & 9.37 & 59 & $65.39 \times 10^{4}$ \\
\hline & Puddling & Stack after BF & 20.93 & 0 & 0 & 0 & 0 & 0.89 & 0.28 & 0.14 & 45 & $17.70 \times 10^{4}$ \\
\hline & Steelmaking & Stack after BF & 20.68 & 0.04 & 0 & 0 & 0 & 1.18 & 0.82 & 0.77 & 56 & $22.42 \times 10^{4}$ \\
\hline \multirow{3}{*}{$\mathrm{D}$} & Sintering & $\begin{array}{l}\text { Stack after ESP } \\
\text { and L-WFGD }\end{array}$ & 16.95 & 4.05 & 3941 & 187 & 201 & 46.27 & 6.62 & 3.61 & 54 & $135.86 \times 10^{4}$ \\
\hline & Puddling & Stack after BF & 20.70 & 0.44 & 29 & 0 & 0 & 2.32 & 0.9 & 0.47 & 40 & $13.28 \times 10^{4}$ \\
\hline & Steelmaking & Stack after BF & 20.41 & 0.43 & 16 & 0 & 0 & 2.99 & 1.55 & 0.84 & 53 & $31.02 \times 10^{4}$ \\
\hline \multirow[t]{2}{*}{$\mathrm{E}$} & Sintering & $\begin{array}{l}\text { Stack after ESP } \\
\text { and SDA-FGD }\end{array}$ & 16.82 & 3.36 & 5565 & 225 & 174 & 20.17 & 1.96 & 0.83 & 82 & $152.93 \times 10^{4}$ \\
\hline & Puddling & Stack after BF & 20.63 & 0.09 & 1220 & 41 & 0 & 16.72 & 11.78 & 7.94 & 72 & $75.01 \times 10^{4}$ \\
\hline
\end{tabular}




\begin{tabular}{|c|c|c|c|c|c|c|c|c|c|c|c|c|}
\hline \multirow{3}{*}{$\mathrm{F}$} & Sintering & $\begin{array}{l}\text { Stack after ESP } \\
\text { and L-WFGD }\end{array}$ & 16.20 & 5.3 & 6483 & 149 & 127 & 33.31 & 18.68 & 8.85 & 52 & $62.07 \times 10^{4}$ \\
\hline & Puddling & Stack after BF & 21.00 & 0 & 0 & 0 & 0 & 5.06 & 2.32 & 1.53 & 43 & $57.91 \times 10^{4}$ \\
\hline & Steelmaking & Stack after BF & 20.91 & 0 & 24 & 0 & 0 & 1.83 & 0.68 & 0.39 & 38 & $73.60 \times 10^{4}$ \\
\hline
\end{tabular}

ESP: electrostatic precipitator; CFB-FGD: circulating fluidized bed flue gas desulfurization;

BF: bag filter; L-WFGD: lime-gypsum wet flue gas desulfurization; A-WFGD: ammonia wet flue gas desulfurization; SDA-FGD: spraying drying adsorption flue gas desulfurization;

T: flue gas temperature; Q: flue gas volume flow at operating condition 
Table 2. Pollutant emission factors of sintering, puddling and steelmaking processes

\begin{tabular}{|c|c|c|c|c|c|c|c|c|}
\hline Process & $\mathrm{P}(\mathrm{t} / \mathrm{h})$ & $\mathrm{K}_{\mathrm{CO} 2}(\mathrm{~kg} / \mathrm{t})$ & $\mathrm{K}_{\mathrm{CO}}(\mathrm{kg} / \mathrm{t})$ & $\mathrm{k}_{\mathrm{SO} 2}(\mathrm{~kg} / \mathrm{t})$ & $\mathrm{k}_{\mathrm{NOx}}(\mathrm{kg} / \mathrm{t})$ & $\mathrm{k}_{\mathrm{TSP}}(\mathrm{kg} / \mathrm{t})$ & $\mathrm{k}_{\mathrm{PM} 10}(\mathrm{~kg} / \mathrm{t})$ & $\mathrm{k}_{\mathrm{PM} 2.5}(\mathrm{~kg} / \mathrm{t})$ \\
\hline \multirow{3}{*}{ Sintering } & 229 & $280.6 \pm 65.5$ & $16.30 \pm 0.09$ & $0.62 \pm 0.004$ & $0.62 \pm 0.003$ & $0.14 \pm 0.001$ & $0.053 \pm 0.0008$ & $0.038 \pm 0.0006$ \\
\hline & -- & $220 \sim 304^{\mathrm{a}}$ & $22^{\mathrm{b}}$ & $3.2^{\mathrm{b}}$ & $0.6^{\mathrm{b}}$ & $1.0^{\mathrm{b}}$ & $0.6^{\mathrm{b}}$ & $0.5^{\mathrm{b}}$ \\
\hline & -- & -- & -- & $2.4 \sim 2.8^{\mathrm{c}}$ & $0.52 \sim 0.61^{\mathrm{c}}$ & $0.40 \sim 1.59^{\mathrm{c}}$ & -- & $0.211 \sim 0.54^{\mathrm{c}}$ \\
\hline \multirow{3}{*}{ Puddling } & 146 & -- & $0.99 \pm 0.02$ & $0.038 \pm 0.02$ & -- & $0.021 \pm 0.0003$ & $0.011 \pm 0.0002$ & $0.008 \pm 0.0001$ \\
\hline & -- & -- & $23.7^{\mathrm{b}}$ & $0.2^{\mathrm{b}}$ & $0.2^{\mathrm{b}}$ & $2.0^{\mathrm{b}}$ & $1.7^{\mathrm{b}}$ & $1.5^{\mathrm{b}}$ \\
\hline & -- & -- & -- & $0.1 \sim 0.13^{\mathrm{c}}$ & $0.15 \sim 0.17^{\mathrm{c}}$ & $0.35 \sim 1.03^{\mathrm{c}}$ & -- & $0.066 \sim 0.114^{\mathrm{c}}$ \\
\hline \multirow{3}{*}{ Steelmaking } & 133 & -- & $0.11 \pm 0.001$ & -- & -- & $0.005 \pm 0.00001$ & $0.0019 \pm 0.00001$ & $0.0012 \pm 0.00001$ \\
\hline & -- & -- & $2.96^{\mathrm{b}}$ & $0.003^{\mathrm{b}}$ & $0.1^{\mathrm{b}}$ & $0.41^{\mathrm{b}}$ & $0.4^{\mathrm{b}}$ & $0.35^{\mathrm{b}}$ \\
\hline & -- & - & - & - & $0.003^{\mathrm{c}}$ & $0.16 \sim 0.26^{\mathrm{c}}$ & - & $0.14 \sim 0.23^{\mathrm{c}}$ \\
\hline
\end{tabular}

${ }^{\text {a }}$ Estimated by the material flow analysis (Xu et. al 2016)

${ }^{\mathrm{b}}$ Estimated by the unite-based bottom-up methodology using data in 2010 (Wang et. al 2016)

${ }^{\mathrm{c}}$ Estimated by the detailed activity level based on the data between 2008-2012 (Wu et. al 2015) 
Table 3. Summary of $\mathrm{PM}_{2.5}$ and $\mathrm{PM}_{10}$ chemical profiles (mass percentage, \%) for sintering, pelleting, puddling and steelmaking

processes

\begin{tabular}{|c|c|c|c|c|c|c|c|c|}
\hline \multirow{2}{*}{ Species } & \multicolumn{2}{|l|}{ Sintering } & \multicolumn{2}{|l|}{ Pelletizing } & \multicolumn{2}{|l|}{ Puddling } & \multicolumn{2}{|l|}{ Steelmaking } \\
\hline & $\mathrm{PM}_{2.5}$ & $\mathrm{PM}_{10}$ & $\mathrm{PM}_{2.5}$ & $\mathrm{PM}_{10}$ & $\mathrm{PM}_{2.5}$ & $\mathrm{PM}_{10}$ & $\mathrm{PM}_{2.5}$ & $\mathrm{PM}_{10}$ \\
\hline $\mathrm{Al}$ & $0.1120 \pm 0.0161$ & $0.1510 \pm 0.0220$ & $1.3345 \pm 0.1993$ & $1.5818 \pm 0.2362$ & $0.3256 \pm 0.0486$ & $0.3100 \pm 0.0459$ & $0.2559 \pm 0.0233$ & $0.2757 \pm 0.0407$ \\
\hline $\mathrm{Si}$ & $0.1464 \pm 0.0115$ & $0.2291 \pm 0.0181$ & $2.5472 \pm 0.2032$ & $2.9136 \pm 0.2324$ & $0.9678 \pm 0.1042$ & $1.0216 \pm 0.1162$ & $1.1639 \pm 0.0821$ & $1.2320 \pm 0.0947$ \\
\hline $\mathrm{Na}$ & $2.0007 \pm 0.1206$ & $2.1614 \pm 0.1306$ & $0.3199 \pm 0.0194$ & $0.3582 \pm 0.0217$ & $0.8848 \pm 0.0947$ & $0.6373 \pm 0.0691$ & $1.0554 \pm 0.2586$ & $1.1414 \pm 0.0691$ \\
\hline $\mathrm{Cl}$ & $23.2158 \pm 1.7195$ & $23.1844 \pm 1.7178$ & $0.1158 \pm 0.0086$ & $0.1147 \pm 0.0085$ & $1.5855 \pm 0.1705$ & $1.2833 \pm 0.1217$ & $2.2511 \pm 0.3698$ & $1.7298 \pm 0.1278$ \\
\hline $\mathrm{Mg}$ & $0.1178 \pm 0.0116$ & $0.1720 \pm 0.0175$ & $0.2542 \pm 0.0288$ & $0.2977 \pm 0.0337$ & $0.2133 \pm 0.0234$ & $0.2145 \pm 0.0269$ & $0.6482 \pm 0.0557$ & $0.7378 \pm 0.0812$ \\
\hline $\mathrm{P}$ & $0.0169 \pm 0.0069$ & $0.0176 \pm 0.0072$ & $0.1755 \pm 0.0723$ & $0.1843 \pm 0.076$ & $0.3377 \pm 0.2529$ & $0.2554 \pm 0.1845$ & $0.1890 \pm 0.0521$ & $0.1797 \pm 0.0741$ \\
\hline$S$ & $2.2865 \pm 0.2573$ & $2.2273 \pm 0.2507$ & $12.4876 \pm 1.4055$ & $9.2001 \pm 1.0355$ & $2.3046 \pm 0.2997$ & $1.8136 \pm 0.2507$ & $1.2103 \pm 0.4760$ & $1.0915 \pm 0.1228$ \\
\hline K & $13.8629 \pm 0.5033$ & $14.0073 \pm 0.5085$ & $0.3390 \pm 0.0123$ & $0.3653 \pm 0.0133$ & $3.2481 \pm 0.1247$ & $2.4263 \pm 0.0889$ & $2.9684 \pm 0.1854$ & $2.2277 \pm 0.0810$ \\
\hline $\mathrm{Ca}$ & $16.5145 \pm 0.3237$ & $13.9974 \pm 0.2688$ & $3.6739 \pm 0.0736$ & $4.2776 \pm 0.0857$ & $2.5228 \pm 0.0593$ & $2.6898 \pm 0.0669$ & $6.9561 \pm 0.0983$ & $9.2782 \pm 0.1843$ \\
\hline $\mathrm{Sc}$ & $0.0093 \pm 0.0012$ & $0.0114 \pm 0.0015$ & $0.0239 \pm 0.0031$ & $0.02510 \pm 0.0033$ & $0.0064 \pm 0.0001$ & $0.0183 \pm 0.0001$ & $0.0200 \pm 0.0206$ & $0.0450 \pm 0.0058$ \\
\hline $\mathrm{Ti}$ & $0.0263 \pm 0.0012$ & $0.0514 \pm 0.0023$ & $0.3390 \pm 0.0149$ & $0.4865 \pm 0.0214$ & $0.1581 \pm 0.0148$ & $0.1909 \pm 0.0156$ & $0.1617 \pm 0.0120$ & $0.1892 \pm 0.0104$ \\
\hline V & $0.0139 \pm 0.0027$ & $0.0110 \pm 0.0022$ & $0.0370 \pm 0.0072$ & $0.0457 \pm 0.0089$ & $0.0436 \pm 0.0027$ & $0.0475 \pm 0.0018$ & $0.0303 \pm 0.0006$ & $0.0662 \pm 0.0129$ \\
\hline $\mathrm{Cr}$ & $0.0236 \pm 0.0012$ & $0.0425 \pm 0.0023$ & $0.0442 \pm 0.0024$ & $0.0696 \pm 0.0037$ & $0.4238 \pm 0.0088$ & $0.4248 \pm 0.0241$ & $0.1758 \pm 0.0414$ & $0.1431 \pm 0.0077$ \\
\hline Mn & $0.0411 \pm 0.0053$ & $0.0674 \pm 0.0087$ & $0.3975 \pm 0.0512$ & $0.5773 \pm 0.0744$ & $0.7752 \pm 0.0761$ & $0.6477 \pm 0.0578$ & $2.5468 \pm 0.4590$ & $2.2859 \pm 0.2945$ \\
\hline $\mathrm{Fe}$ & $2.6593 \pm 0.0430$ & $8.3294 \pm 0.1338$ & $38.0058 \pm 0.6065$ & $63.1871 \pm 1.0084$ & $62.9337 \pm 1.0939$ & $64.1883 \pm 1.1603$ & $72.6680 \pm 0.9233$ & $64.0949 \pm 1.0382$ \\
\hline Co & $0.0028 \pm 0.0009$ & $0.0092 \pm 0.0028$ & $0.0394 \pm 0.0118$ & $0.0580 \pm 0.0174$ & $0.0577 \pm 0.0061$ & $0.0607 \pm 0.0165$ & $0.0596 \pm 0.0036$ & $0.0681 \pm 0.0204$ \\
\hline $\mathrm{Ni}$ & $0.0147 \pm 0.0036$ & $0.0267 \pm 0.0066$ & $0.0263 \pm 0.0066$ & $0.0309 \pm 0.0077$ & $0.1589 \pm 0.0239$ & $0.1574 \pm 0.0393$ & $0.0490 \pm 0.0643$ & $0.0399 \pm 0.0100$ \\
\hline $\mathrm{Cu}$ & $0.4301 \pm 0.0914$ & $0.3643 \pm 0.0774$ & $0.0251 \pm 0.0053$ & $0.0309 \pm 0.0066$ & $0.0503 \pm 0.0310$ & $0.0550 \pm 0.0440$ & $0.0407 \pm 0.0206$ & $0.0516 \pm 0.0110$ \\
\hline $\mathrm{Zn}$ & $0.3647 \pm 0.0649$ & $0.3707 \pm 0.0660$ & $0.0155 \pm 0.0028$ & $0.0206 \pm 0.0037$ & $1.8334 \pm 1.4811$ & $1.4323 \pm 1.0580$ & $1.5646 \pm 1.2470$ & $1.3043 \pm 0.2319$ \\
\hline
\end{tabular}




\begin{tabular}{lcccccccc}
$\mathrm{As}$ & $0.0001 \pm 0.00000$ & $0.0001 \pm 0.0001$ & $0.0740 \pm 0.0553$ & $0.0804 \pm 0.0600$ & $0.0086 \pm 0.0185$ & $0.0060 \pm 0.0108$ & $0.0019 \pm 0.0026$ & $0.0014 \pm 0.0010$ \\
$\mathrm{Se}$ & $0.1926 \pm 0.0622$ & $0.1631 \pm 0.0527$ & $0.1170 \pm 0.0378$ & $0.1121 \pm 0.0362$ & $0.0298 \pm 0.0006$ & $0.0294 \pm 0.0060$ & $0.0250 \pm 0.0001$ & $0.0235 \pm 0.0076$ \\
$\mathrm{Br}$ & $1.0958 \pm 0.2398$ & $1.0185 \pm 0.2229$ & $0.0704 \pm 0.0154$ & $0.0722 \pm 0.0158$ & $0.1265 \pm 0.0174$ & $0.1406 \pm 0.0176$ & $0.2179 \pm 0.0557$ & $0.2462 \pm 0.0539$ \\
$\mathrm{Sr}$ & $0.0019 \pm 0.0003$ & $0.0017 \pm 0.0003$ & $0.0227 \pm 0.004$ & $0.0296 \pm 0.0052$ & $0.0183 \pm 0.0132$ & $0.0270 \pm 0.0222$ & $0.0444 \pm 0.0204$ & $0.0669 \pm 0.0116$ \\
$\mathrm{Cd}$ & $0.0354 \pm 0.0025$ & $0.0537 \pm 0.0037$ & $0.0585 \pm 0.0041$ & $0.0735 \pm 0.0051$ & $0.0976 \pm 0.0141$ & $0.1403 \pm 0.0194$ & $0.2358 \pm 0.0270$ & $0.2859 \pm 0.0199$ \\
$\mathrm{Ba}$ & $0.0297 \pm 0.0015$ & $0.0601 \pm 0.0030$ & $0.0859 \pm 0.0043$ & $0.0844 \pm 0.0042$ & $0.0321 \pm 0.0001$ & $0.1193 \pm 0.0071$ & $0.2958 \pm 0.0008$ & $0.2068 \pm 0.0108$ \\
$\mathrm{~Pb}$ & $3.3124 \pm 0.3622$ & $3.0056 \pm 0.3287$ & $0.0561 \pm 0.0061$ & $0.0612 \pm 0.0067$ & $0.3120 \pm 0.0562$ & $0.2561 \pm 0.0504$ & $0.4507 \pm 0.1647$ & $0.4425 \pm 0.0484$ \\
$\mathrm{Sn}$ & $0.0655 \pm 0.0100$ & $0.0943 \pm 0.0144$ & $0.1289 \pm 0.0198$ & $0.1321 \pm 0.0202$ & $0.1418 \pm 0.0003$ & $0.1995 \pm 0.0004$ & $0.3404 \pm 0.0012$ & $0.4372 \pm 0.0670$ \\
$\mathrm{Sb}$ & $3.6541 \pm 0.1106$ & $3.7733 \pm 0.1142$ & $0.1349 \pm 0.0041$ & $0.1379 \pm 0.0042$ & $0.8006 \pm 0.0272$ & $0.6580 \pm 0.0271$ & $0.7346 \pm 0.0518$ & $0.6160 \pm 0.0187$ \\
$\mathrm{NO}_{3}{ }^{-}$ & $0.5228 \pm 0.0046$ & $0.4915 \pm 0.0043$ & $0.2080 \pm 0.0018$ & $0.05610 \pm 0.0005$ & $0.4864 \pm 0.0009$ & $2.5653 \pm 0.0021$ & $0.0253 \pm 0.0003$ & $0.8394 \pm 0.0074$ \\
$\mathrm{SO}_{4}{ }^{2-}$ & $13.0426 \pm 0.2240$ & $12.3804 \pm 0.2127$ & $36.8721 \pm 0.6335$ & $14.2077 \pm 0.2441$ & $7.0717 \pm 0.0278$ & $6.5849 \pm 0.0244$ & $0.8001 \pm 0.0112$ & $8.0301 \pm 0.1380$ \\
$\mathrm{NH}_{4}{ }^{+}$ & $8.9182 \pm 0.0759$ & $7.6223 \pm 0.0649$ & $1.9706 \pm 0.0168$ & $1.1278 \pm 0.0096$ & $2.2678 \pm 0.0006$ & $1.7065 \pm 0.0004$ & $0.0288 \pm 0.0003$ & $0.0497 \pm 0.0004$ \\
$\mathrm{OC}^{-}$ & $6.0057 \pm 0.1802$ & $4.9582 \pm 0.1488$ & $0.0000 \pm 0.0000$ & $0.0000 \pm 0.0000$ & $4.0097 \pm 0.0149$ & $4.2022 \pm 0.0138$ & $0.2714 \pm 0.0214$ & $0.2082 \pm 0.0062$ \\
$\mathrm{EC}$ & $0.3169 \pm 0.0094$ & $0.2286 \pm 0.0068$ & $0.0000 \pm 0.0000$ & $0.0000 \pm 0.0000$ & $4.1656 \pm 0.0015$ & $3.8903 \pm 0.0014$ & $0.0000 \pm 0.0000$ & $0.0000 \pm 0.0000$ \\
\hline
\end{tabular}

